


\title{
Computer-aided Harmonic Progression Analysis: CAT CaSe
}

\author{
Carmine Cataldo*, Luigi Serra** \\ * PhD in Mechanical Engineering, MD in Disciplines of Jazz and Improvisation - Jazz Piano, Battipaglia (SA), Italy \\ ** R. A., ISISLab, Department of Computer Science, University of Salerno (Italy)
}

\begin{abstract}
In this article we briefly introduce CAT CaSe. CAT CaSe is an innovative Android app, entirely based on an improved version of CAT (Cataldo Advanced Transformations), expressly meant for musicians (professionals and students). The app allows to instantly carry out a detailed analysis of any harmonic progression, without any exception whatsoever. All the phases that constitute the analysis are shown to the user, and the Harmonic Substitutions that occur are accurately discussed.
\end{abstract}

\section{Keywords}

CAT CaSe, Android, Cataldo Advanced Transformations, Chord Progression Analysis, Harmonic Substitutions.

\section{CAT CaSe}

CAT CaSe [https://play.google.com/store/apps/details?id=serra.cataldo.catcase] is an innovative Android application (developed by Carmine Cataldo e Luigi Serra), entirely based on an improved version of CAT (Cataldo Advanced Transformations) [1], expressly meant for musicians (professionals and students). The app allows to instantly carry out a detailed analysis of any harmonic progression, without any exception whatsoever. All the phases that constitute the analysis are shown to the user, and the Harmonic Substitutions [2] [3] [4] [5] that occur are accurately discussed. For instance, every time the app resorts to the so-called "Modal Interchange", the scales between which the parallelism is set are revealed (CAT CaSe can compare up to 35 scales/modes), highlighting the degrees which are involved.
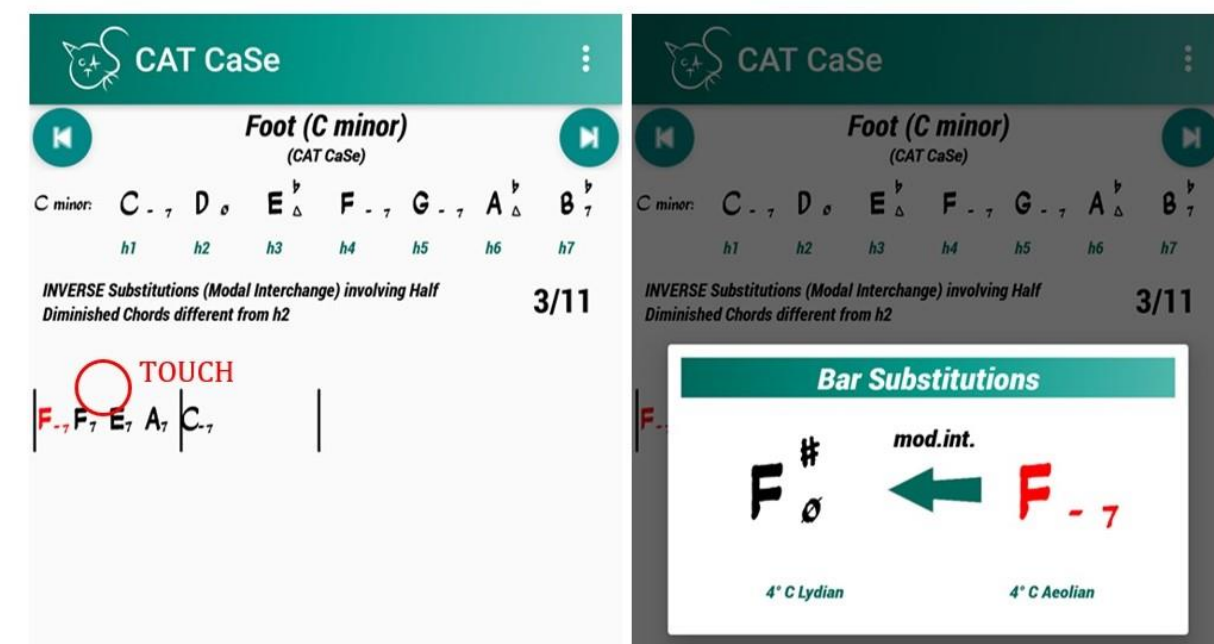

CAT CaSe, moreover, can recognize and contextualize possible "Harmonic Enrichments", such as "Tonicizations" and "Expansions" (half-cadences arisen from a single Dominant Seventh Chord). [2] [3] [4] [5]

CAT CaSe is provided with a didactic section, finalized to rigorously defining all the Harmonic Substitutions and the Enrichments. 


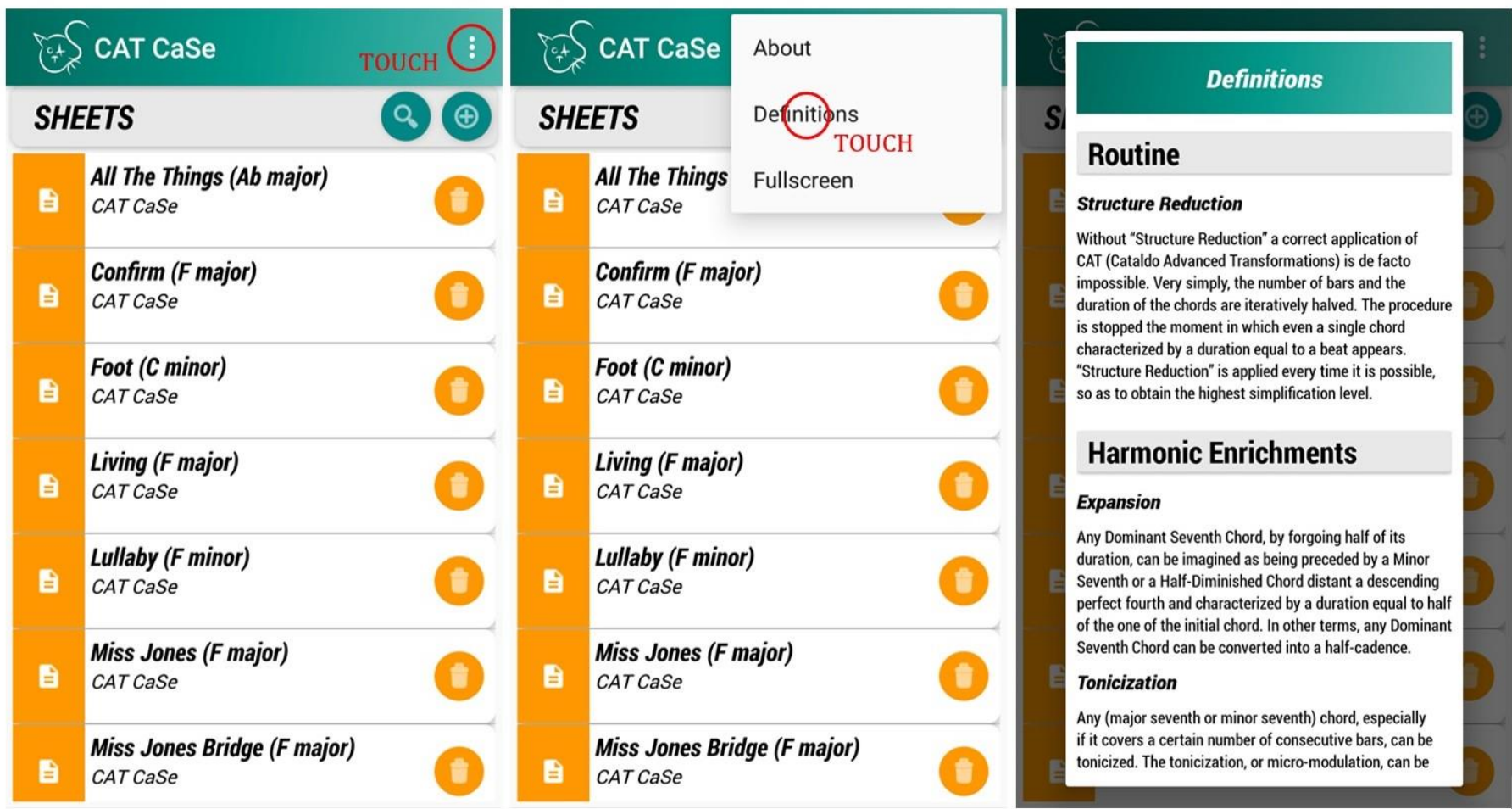

The writing of harmonic progressions is extremely simple and incredibly fast, thanks to the introduction of an innovative interface that allows the user to completely avoid the usage of the alphanumeric keypad. For this reason, CAT CaSe turns out to be very useful during live performances, especially if it is necessary to quickly and comprehensibly write, by exploiting an Android device (smarthpone or tablet), a harmonic progression the musician must abide to during the accompaniment or the improvisation.

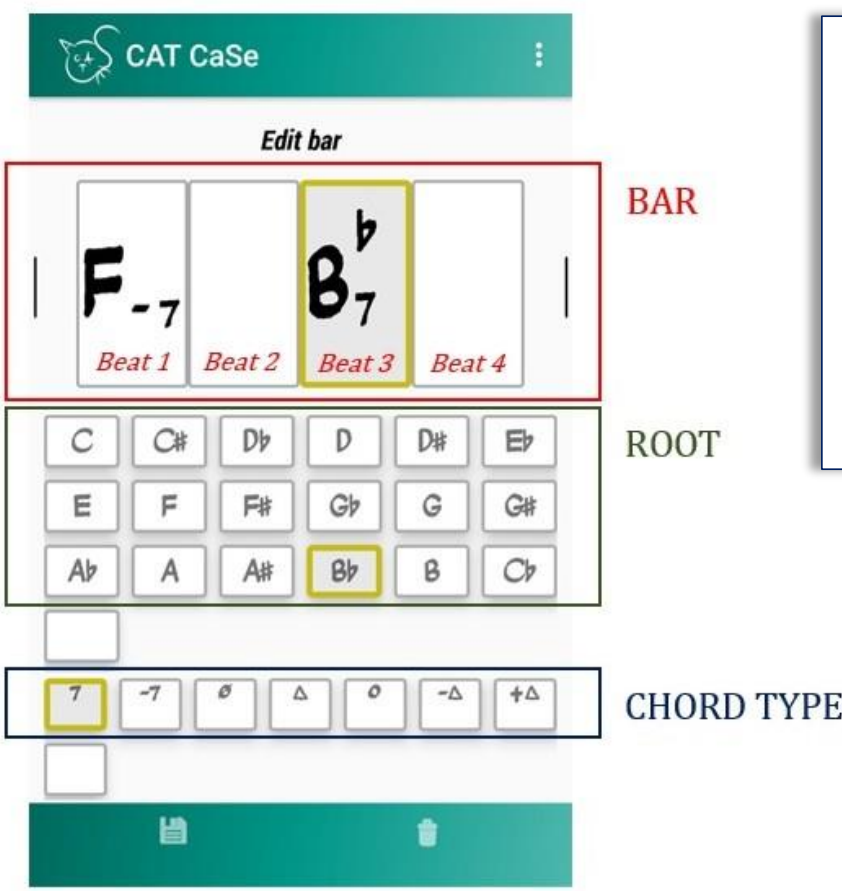

The time signature must always be imagined as being equal to $4 / 4$. For example, even if we deal with a $3 / 4$, we have to consider four pulses per measure (four beats per bar): each beat, in this case, will be characterized by a duration equivalent to a dotted quaver.

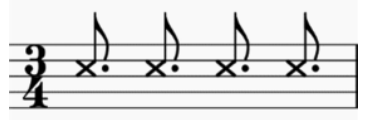

After the analysis, CAT CaSe allows the user to examine an "inverse procedure", particularly dedicated to musicians interested in composing and arranging. In a few words, starting from the final outcome of the analysis (very often, a sequence of plagal and/or perfect cadences) [4] [5], the app returns, step by step, the initial progression. As a useful additional feature, on the first page of the inverse procedure the parametric version (regardless of the particular key) of the final outcome is also shown. 


\section{CAT (Cataldo Advanced Transformations): Short Overview}

CAT CaSe is entirely based on an improved version of CAT (Cataldo Advanced Transformations). A considerable improvement of $C A T$ has been achieved by conducting an extremely thorough analysis of a huge amount of LEGO Bricks (public domain harmonic patterns) [6] [7].

Unlike the previous one [8] [9], the ultimate version of CAT [1] has no limitation concerning the key (any song written in both major and minor key can be analysed), exploits a more rigorous definition of "Similitude", and takes into consideration "Modal Interchange" and "Tonicization".

\section{Examples}

\section{Example \#1 (Major Key): "Inner Urge" (Joe Henderson) - last 8bars}

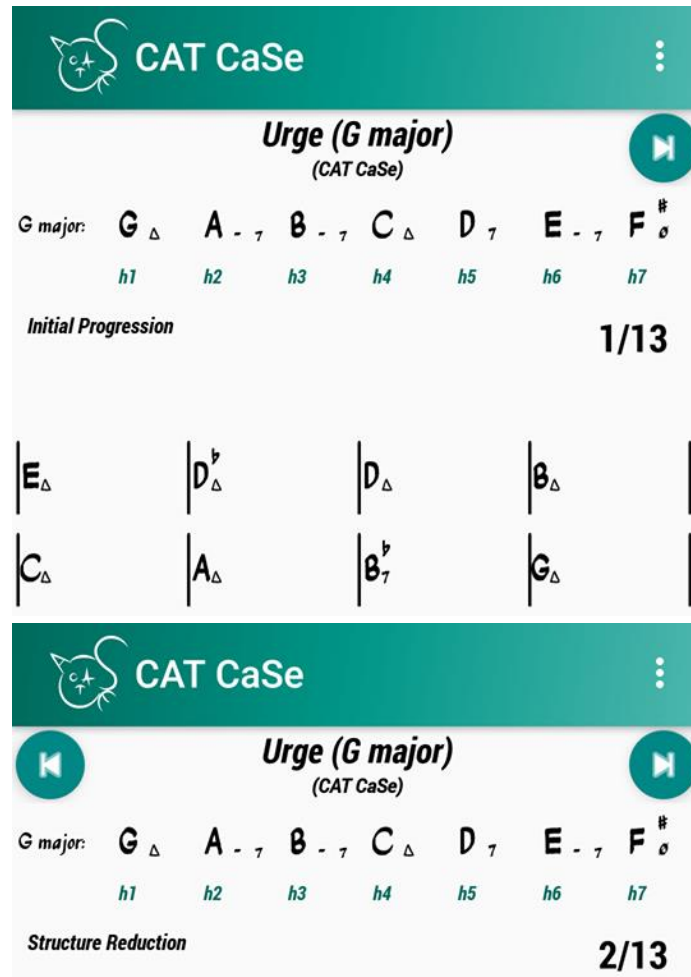

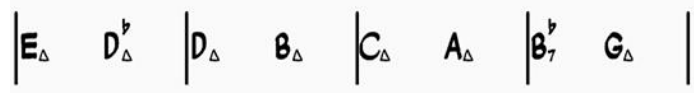

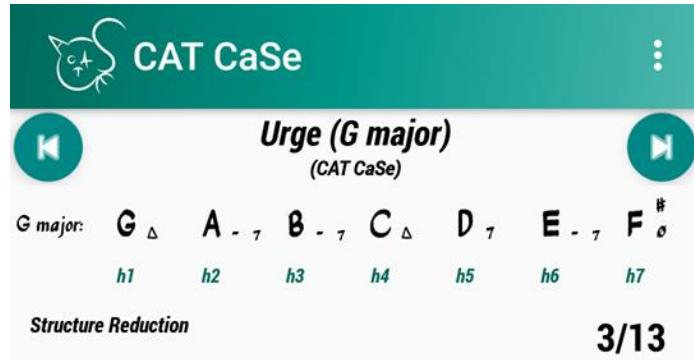

$\left|E_{\Delta} D_{\Delta}^{b} D_{\Delta} B_{\Delta}\right| C_{\Delta} A_{\Delta} B_{7}^{b} G_{\Delta} \mid$

\section{INITIAL STRUCTURE and HARMONIZATION VECTOR}

Harmonization Vector - The vector whose components represent the seventh chords that arise from the harmonization of the scale (in this case, the Ionian of $F$ ) [10] [11].

\section{STRUCTURE REDUCTION}

Structure Reduction - Without "Structure Reduction" a correct application of CAT (Cataldo Advanced Transformations) is de facto impossible. Very simply, the number of bars and the duration of the chords are iteratively halved. The procedure is stopped the moment in which even a single chord characterized by a duration equal to a beat appears. "Structure Reduction" is applied every time it is possible, so as to obtain the highest simplification level [1] [8] [9].

\section{STRUCTURE REDUCTION}

*See point 2 for the definition of Structure Reduction 


\section{CAT CaSe}

Urge (G major)
(CATCaSe)

INVERSE Substitutions (Modal Interchange) involving Major Seventh Chords different from $h 1$ and $h 4$

$4 / 13$

$\left|\begin{array}{ll}F_{0}^{*} D_{7} & B_{-.} \mid C_{\Delta} B_{-,} B_{7}^{b} G_{\Delta}\end{array}\right|$
4. Inverse Substitutions (Modal Interchange*) involving MAJOR SEVENTH CHORDS different from $h_{1}$ and $h_{4}$

Modal Interchange - Two chords that arise from the harmonization of two different scales characterized by the same tonic (generic parallel keys) are interchangeable if they are placed in the same position (if they represent the same harmonic degree) [1] [4] [5].

\section{Bar Substitutions}

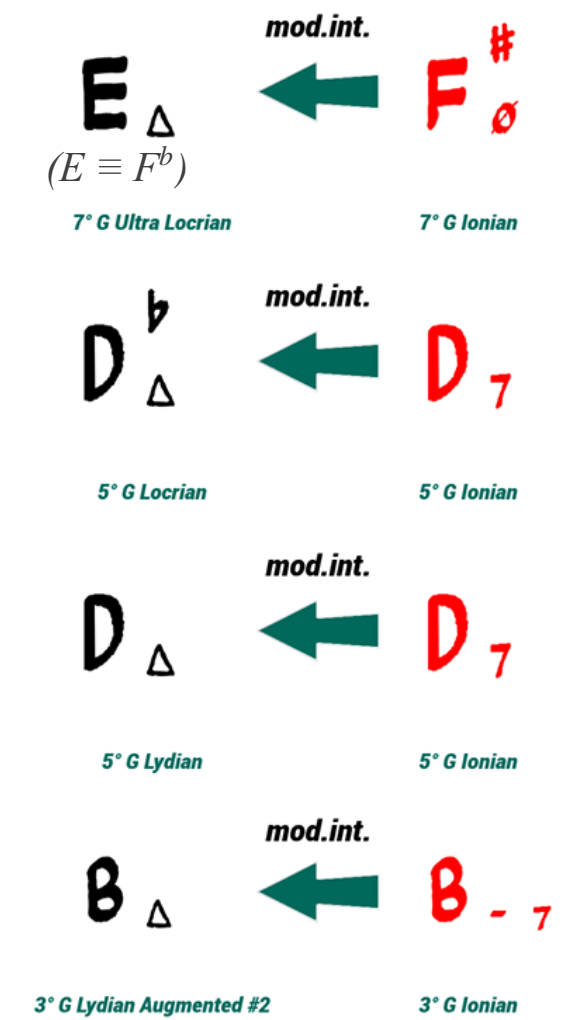

\section{Bar Substitutions}

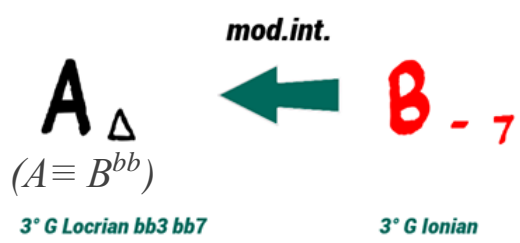

Tritone Substitution - Any Dominant Seventh Chord, especially if altered, can be replaced, even if it were to arise from a previous harmonic substitution, by a chord of the same kind (a Dominant Seventh Chord) distant three whole tones from the initial chord [1] [2] [3] [4] [5] [8] [9].

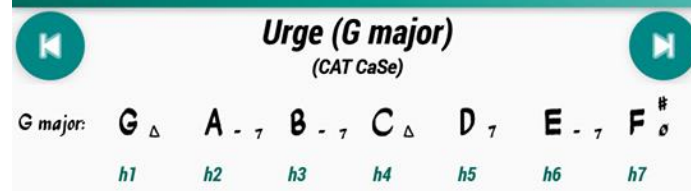

(INVERSE) Tritone Substitutions

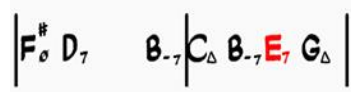




\section{CAT CaSe}

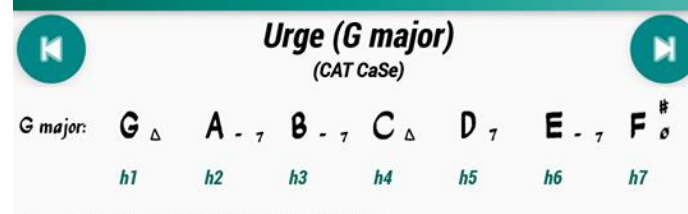

Secondary Dominants INVERSE Substitutions

$6 / 13$

\section{CAT CaSe}

\section{(1) Urge (G major)}

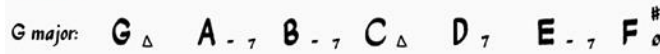
${ }_{h 1} \quad h_{2} \quad h_{33} \quad{ }_{h 4} \quad h_{5} \quad h_{6} \quad{ }_{h 7}$

(INVERSE) Diatonic Substitutions involving h6

$7 / 13$

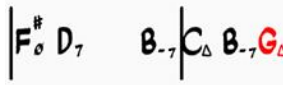

\section{SECONDARY DOMINANTS Inverse Substitutions}

Secondary Dominant Substitution - Any chord, even if it were to arise from a previous harmonic substitution, can be converted into a Dominant Seventh Chord [1] [2] [3] [4] [5] [8] [9].

7. (Inverse) DIATONIC Substitutions involving $h_{6}$

Diatonic Substitution - Two chords that arise from the harmonization of the same scale are interchangeable if the distance between them (between the roots) is equal to a diatonic third (both ascending and descending) [1] [2] [3] [4] [5] [8] [9].

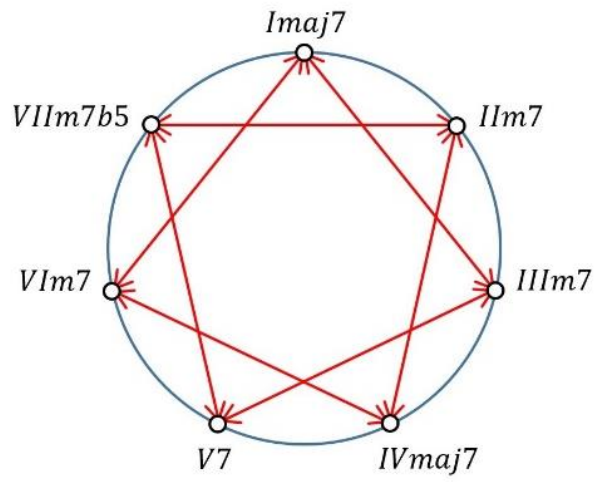

8. (Inverse) DIATONIC Substitutions involving $h_{3}$ *See point 7 for the definition of Diatonic Substitution

\section{(1) Urge (G major) (CAT CaSe)

(INVERSE) Diatonic Substitutions involving h3

$\mid F_{0}^{\#} D_{7} \quad C_{\Delta} D_{7} G_{\Delta}$

\section{CAT CaSe}

\section{(1) Urge (G major) (CAT CaSe)}

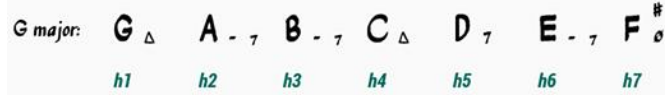

(INVERSE) Diatonic Substitutions involving h7
9. (Inverse) DIATONIC Substitutions involving $h_{7}$

* See point 7 for the definition of Diatonic Substitution

$\left|D_{7} \quad\right| C_{\Delta} D_{7} G_{\Delta}$ 


\section{CAT CaSe}

\section{Urge (G major)}

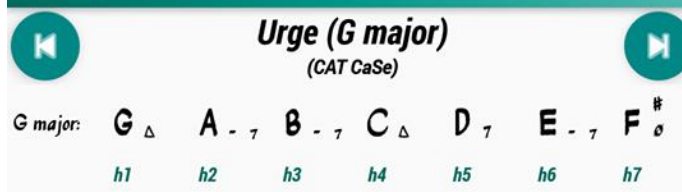

(INVERSE) Diatonic Substitutions involving h2 and h4
10. (Inverse) DIATONIC Substitutions involving $h_{2}$ and $h_{4}$

*See point 7 for the definition of Diatonic Substitution
$\left|D_{7} \quad\right| A-D_{7} G_{\Delta} \mid$

\section{CAT CaSe}

\section{(1) Urge (G major) (CAT CaSe)}

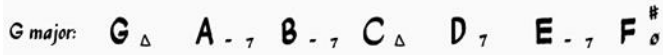
$\begin{array}{lllllll}h 1 & h 2 & h 3 & h 4 & h 5 & h 6 & h 7\end{array}$

Contractions (INVERSE Expansion Substitutions)

\section{$11 / 13$}

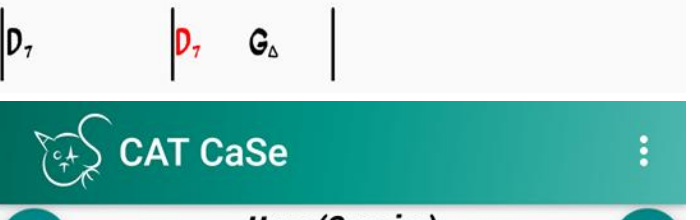

\section{(1) Urge (G major)}

$G_{\text {major }} G_{\Delta} A ., B_{.}, C_{\Delta} \quad D_{7} E ., F_{0}^{\#}$

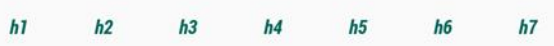

Structure Reduction

$12 / 13$

\section{$\left|\begin{array}{ll}D_{7} & G_{\Delta}\end{array}\right|$}

\section{CAT CaSe}

\section{(1) Urge (G major)}

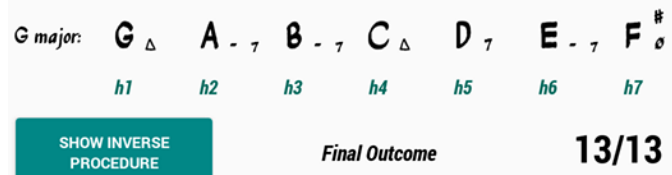

$\vdots$

13. FINAL OUTCOME

\section{CONTRACTION (Inverse EXPANSION)}

Expansion - Any Dominant Seventh Chord, by forgoing half of its duration, can be imagined as being preceded by a Minor Seventh or a Half-Diminished Chord distant a descending perfect fourth and characterized by a duration equal to half of the one of the initial chord. In other terms, any Dominant Seventh Chord can be converted into a half-cadence [1] [2] [3] [8] [9].

\section{STRUCTURE REDUCTION}

*See point 2 for the definition of Structure Reduction

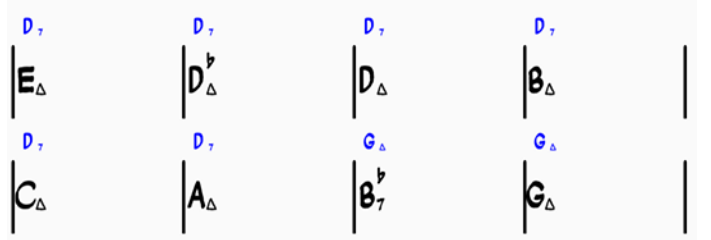




\section{JOSHA}

Journal of Science,

Humanities and Arts

\section{Inverse Procedure}

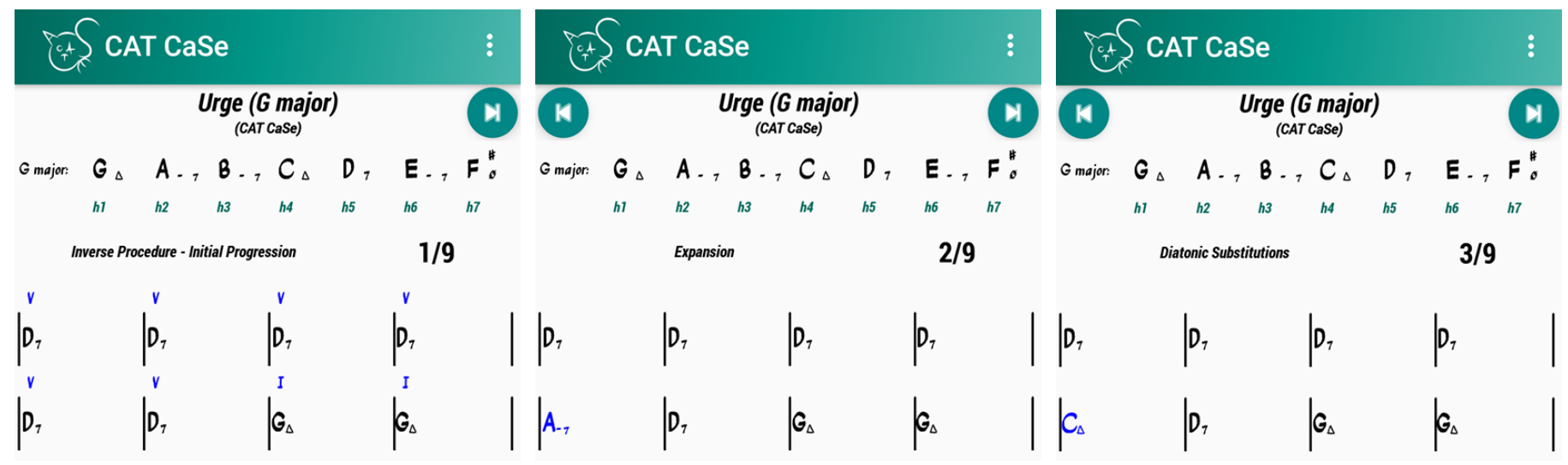

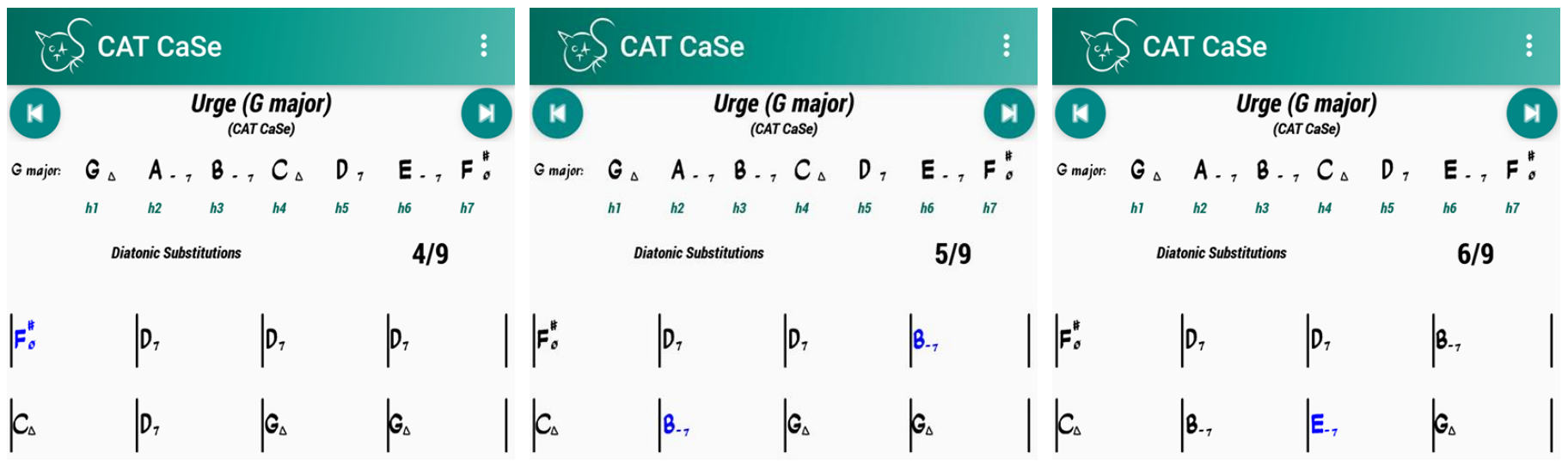

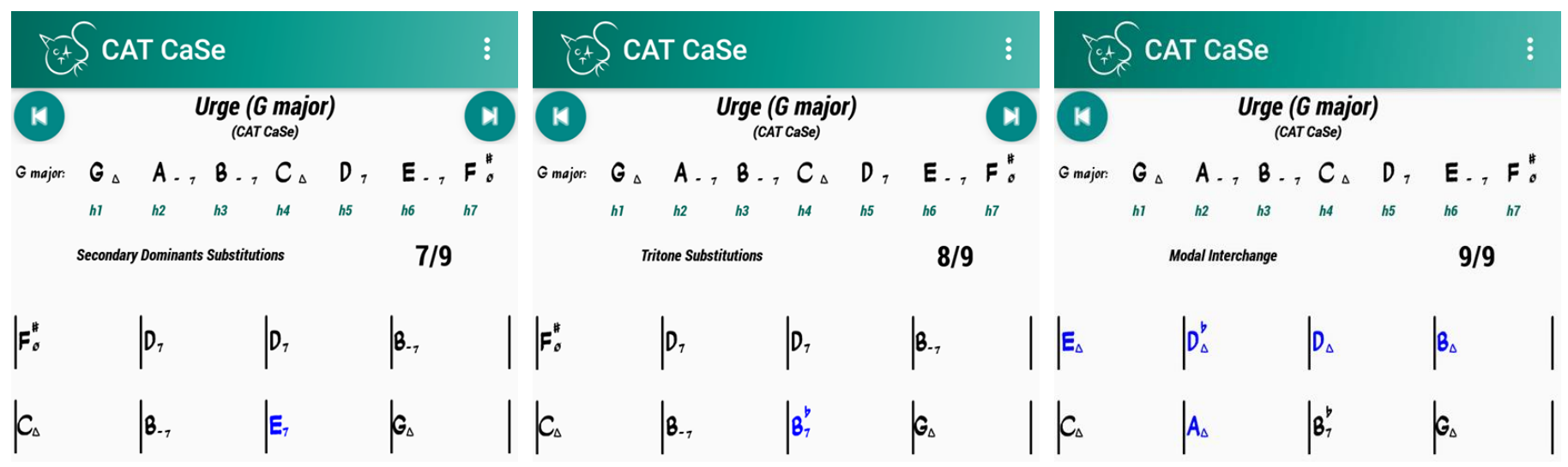


Example \#2 (Minor Key): "Lullaby of Birdland” (George Shearing) - first 8 bars

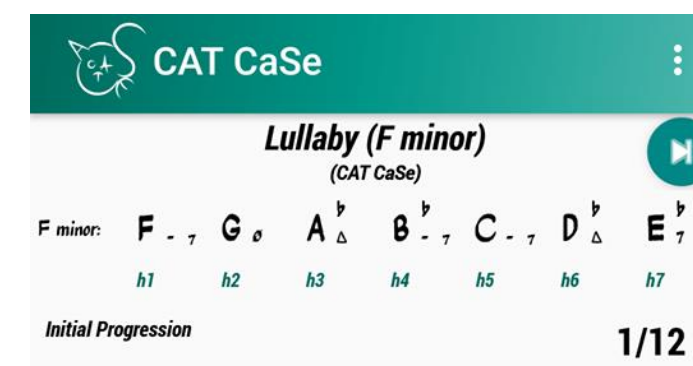

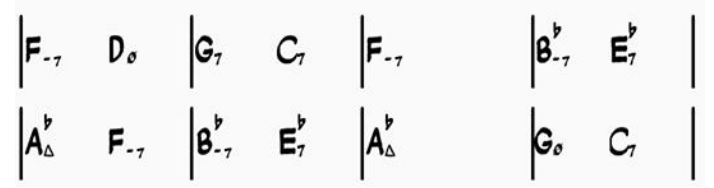
CAT CaSe

\begin{tabular}{|c|c|c|c|c|c|c|c|}
\hline \multirow[b]{2}{*}{$F_{\text {minor: }}$} & \multicolumn{6}{|c|}{$\underset{\text { (CAT CaSe) }}{\text { Lullaby (F minor) }}$} & \\
\hline & F . , & G. & $A_{\Delta}^{b}$ & $B^{b}=$ & C., & $D_{\Delta}^{b}$ & E \\
\hline & $h 1$ & $h 2$ & $h 3$ & $h 4$ & $h 5$ & $h 6$ & $h 7$ \\
\hline
\end{tabular}

$\left|F_{-, 7} D_{0} G_{7} C_{7}\right| F_{-7} \quad B_{-, 7}^{b} E_{7}^{b}\left|A_{\Delta}^{b} F_{-, 7} B_{-,}^{b} E_{7}^{b}\right| A_{\Delta}^{b} \quad G_{0} C_{7} \mid$ CAT CaSe

\begin{tabular}{|c|c|c|c|c|c|}
\hline n & \multicolumn{5}{|c|}{$\underset{\text { (CATCaSe) }}{\text { Lullaby (F minor) }}$} \\
\hline$F$ minor: & $F \ldots, G_{0}$ & $A_{\Delta}^{b}$ & $B^{b} \cdot$, & C., & $D_{\Delta}^{b}$ \\
\hline & h2 & $h 3$ & $h 4$ & $h 5$ & h6 \\
\hline
\end{tabular}

$\left|F_{-7} D_{0} G_{7} C_{7}\right| F_{-7} \quad E_{7}^{b} \quad\left|\begin{array}{llll}A_{\Delta}^{b} F_{-7} E_{7}^{b} & \mid A_{\Delta}^{b} & C_{7}\end{array}\right|$ CAT CaSe

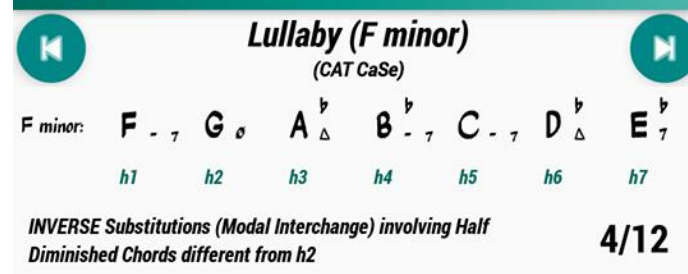
Diminished Chords different from $h 2$

$4 / 12$

\section{INITIAL STRUCTURE and HARMONIZATION VECTOR}

Harmonization Vector - The vector whose components represent the seventh chords that arise from the harmonization of the scale (in this case, the Aeolian of $F$ ) [10] [11].

\section{STRUCTURE REDUCTION}

Structure Reduction - Without "Structure Reduction" a correct application of CAT (Cataldo Advanced Transformations) is de facto impossible. Very simply, the number of bars and the duration of the chords are iteratively halved. The procedure is stopped the moment in which even a single chord characterized by a duration equal to a beat appears. "Structure Reduction" is applied every time it is possible, so as to obtain the highest simplification level [1] [8] [9].

\section{CONTRACTION (Inverse EXPANSION)}

Expansion - Any Dominant Seventh Chord, by forgoing half of its duration, can be imagined as being preceded by a Minor Seventh or a Half-Diminished Chord distant a descending perfect fourth and characterized by a duration equal to half of the one of the initial chord. In other terms, any Dominant Seventh Chord can be converted into a half-cadence [1] [2] [3] [8] [9].

4. Inverse Substitutions (Modal Interchange) involving HALF DIMINISHED CHORDS different from $h_{2}$

Modal Interchange - Two chords that arise from the harmonization of two different scales characterized by the same tonic (generic parallel keys) are interchangeable if they are placed in the same position (if they represent the same harmonic degree) [1] [4] [5].

\section{Bar Substitutions}

$\left|F_{-7} D_{\Delta}^{b} G_{7} C_{7}\right| F_{-7} \quad E_{7}^{b} \quad\left|\begin{array}{llll}A_{\Delta}^{b} F_{-7} E_{7}^{b} & \mid A_{\Delta}^{b} & C_{7}\end{array}\right|$

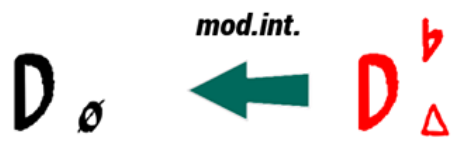




\section{CAT CaSe}

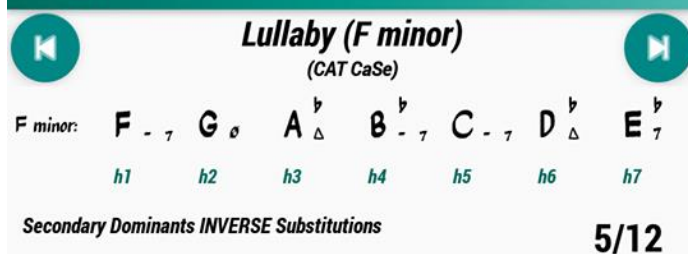

$\left|F_{-,} D_{\Delta}^{b} G_{0} C_{7}\right| F_{-7} \quad E_{7}^{b} \quad\left|\begin{array}{llll}A_{\Delta}^{b} F_{-7} E_{7}^{b} & \mid A_{\Delta}^{b} & C_{7}\end{array}\right|$

\section{CAT CaSe}

$\vdots$

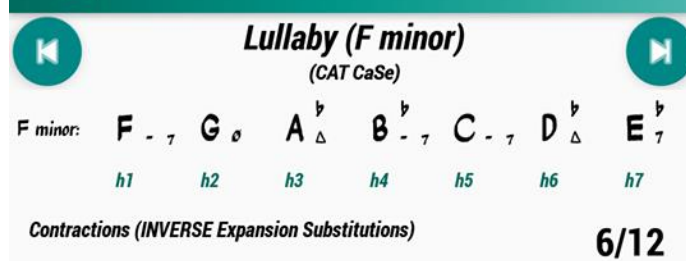

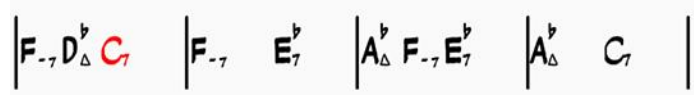
CAT CaSe

\section{(1) Lullaby (F minor)}

F minor: $F ., G, A_{\Delta}^{b} B^{b}, C ., D_{\Delta}^{b} E_{7}^{b}$ $\begin{array}{lllllll}h 1 & h 2 & h 3 & h 4 & h 5 & h 6 & h 7\end{array}$

(INVERSE) Diatonic Substitutions involving h6

$7 / 12$

$\left|\begin{array}{llll|ll|l|l|}F_{-7} & C_{7} & \mid F_{-7} & E_{7}^{b} & \mid A_{\Delta}^{b} F_{-,} E_{7}^{b} & \mid A_{\Delta}^{b} & C\end{array}\right|$

\section{SECONDARY DOMINANTS Inverse Substitutions}

Secondary Dominant Substitution - Any chord, even if it were to arise from a previous harmonic substitution, can be converted into a Dominant Seventh Chord [1] [2] [3] [4] [5] [8] [9].

\section{CONTRACTION (Inverse EXPANSION)}

*See point 3 for the definition of Contraction
7. (Inverse) DIATONIC Substitutions involving $h_{6}$

Diatonic Substitution - Two chords that arise from the harmonization of the same scale are interchangeable if the distance between them (between the roots) is equal to a diatonic third (both ascending and descending [1] [2] [3] [4] [5] [8] [9].

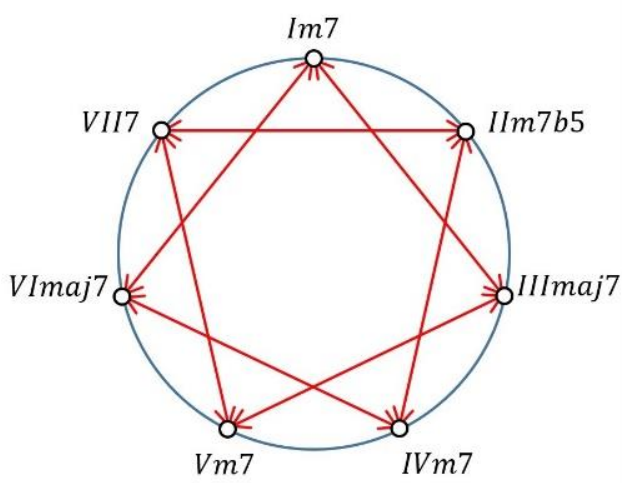

8. (Inverse) DIATONIC Substitutions involving $h_{3}$

*See point 7 for the definition of Diatonic Substitution

\section{CAT CaSe}

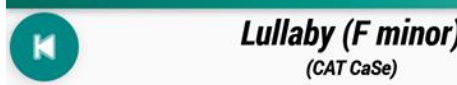

$$
\begin{array}{rlllllll}
F_{\text {minor: }} & \boldsymbol{F} ., & \mathbf{G}_{0} & \mathbf{A}_{\Delta}^{b} & \mathbf{B}_{-}^{b}, & \mathbf{C .}_{-} & \mathbf{D}_{\Delta}^{b} & \mathbf{E}_{7}^{b} \\
& h 1 & h 2 & h 3 & h 4 & h 5 & h 6 & h 7
\end{array}
$$

(INVERSE) Diatonic Substitutions involving h3

$8 / 12$

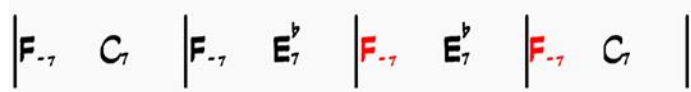




\section{CAT CaSe}

(1) Lullaby (F minor)

$$
\begin{aligned}
& \text { F minor: } F ., G_{0} A_{\Delta}^{b} B_{-}^{b}, C ., D_{\Delta}^{b} E^{b} \\
& \begin{array}{lllllll}
h 1 & h 2 & h 3 & h 4 & h 5 & h 6 & h 7
\end{array}
\end{aligned}
$$

(INVERSE) Diatonic Substitutions involving $h 7$

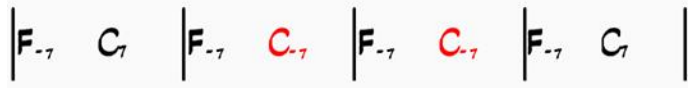

\section{CAT CaSe}

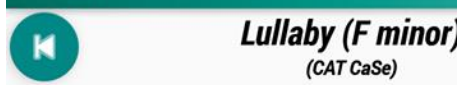

$$
\begin{aligned}
& \text { Fminor: } F ., G_{0} A_{\Delta}^{b} B_{-}^{b}, C ., D_{\Delta}^{b} E_{7}^{b} \\
& \begin{array}{lllllll}
h 1 & h 2 & h 3 & h 4 & h 5 & h 6 & h 7
\end{array}
\end{aligned}
$$

Structure Reduction

$\left|F_{-,} C_{7} F_{-,} C_{-,}\right| F_{-,} C_{-}, F_{-,} C_{7} \mid$

\section{CAT CaSe}

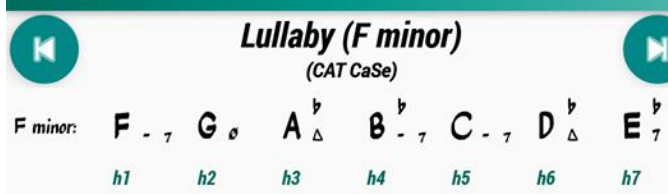

Further Secondary Dominants INVERSE Substitutions

$\left|F_{-,} C_{-7} F_{-7} C_{-.7}\right| F_{-7} C_{-7} F_{-7} C_{-7} \mid$

\section{CAT CaSe}

12. FINAL OUTCOME
9. (Inverse) DIATONIC Substitutions involving $h_{7}$

*See point 7 for the definition of Diatonic Substitution

\section{STRUCTURE REDUCTION}

* See point 2 for the definition of Structure Reduction
11. Further SECONDARY DOMINANT Inverse Substitutions *See point 5 for the definition of Secondary Dom. Substitutions

\section{(1) Lullaby (F minor)}

F minor: $F,, G_{0} A_{\Delta}^{b} B^{b}, C ., D_{\Delta}^{b} E_{7}^{b}$ h1 h2

\section{SHOW INVERSE
PROCEDURE}

h3

Final Outcome

$12 / 12$$$
\text { pro }
$$

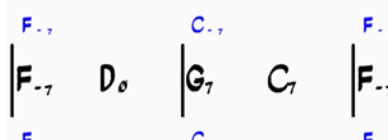

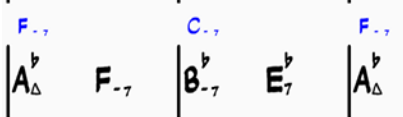

$$
\begin{aligned}
& \left|\begin{array}{ll}
c ., & \\
B_{-7}^{b} & E_{7}^{b}
\end{array}\right| \\
& \left|\begin{array}{ll}
G_{0} & C_{7}
\end{array}\right|
\end{aligned}
$$




\section{Inverse Procedure}

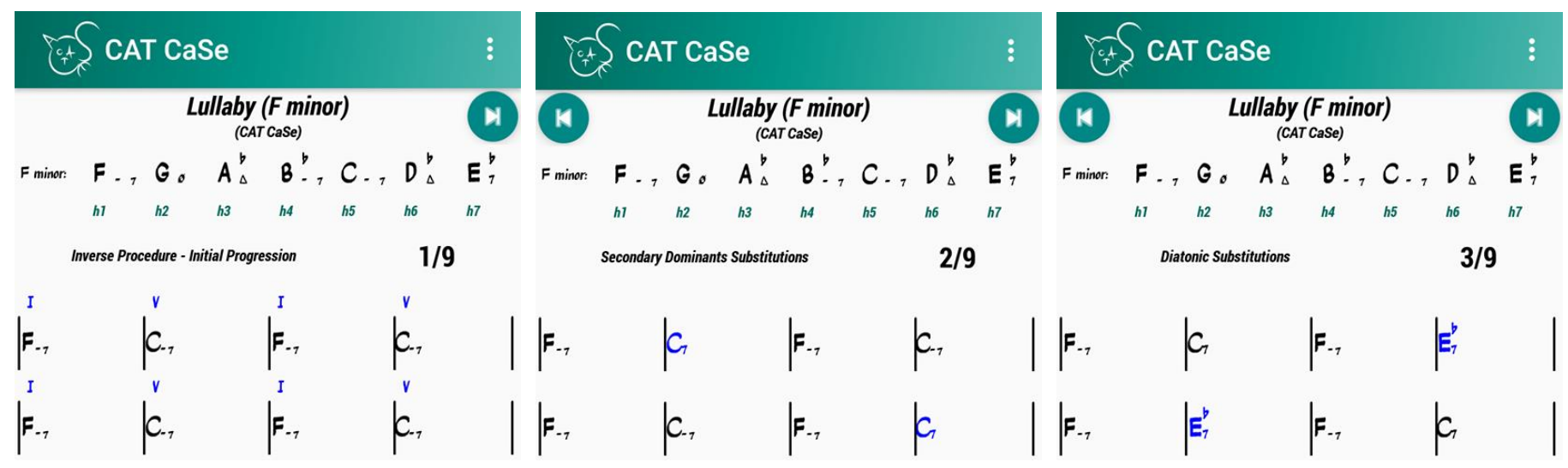

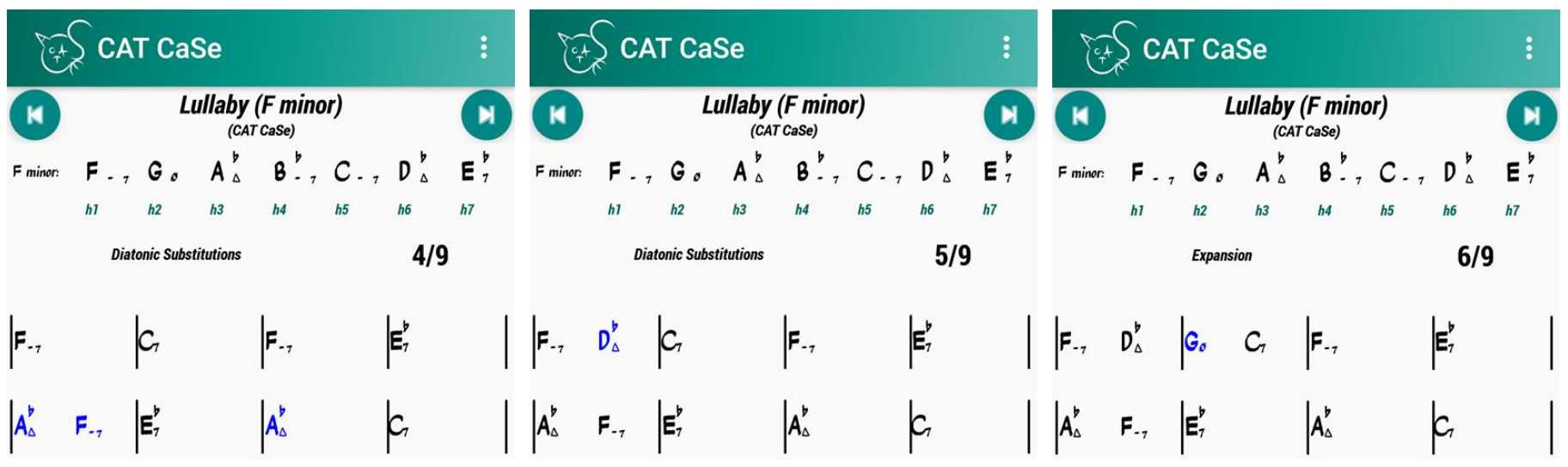

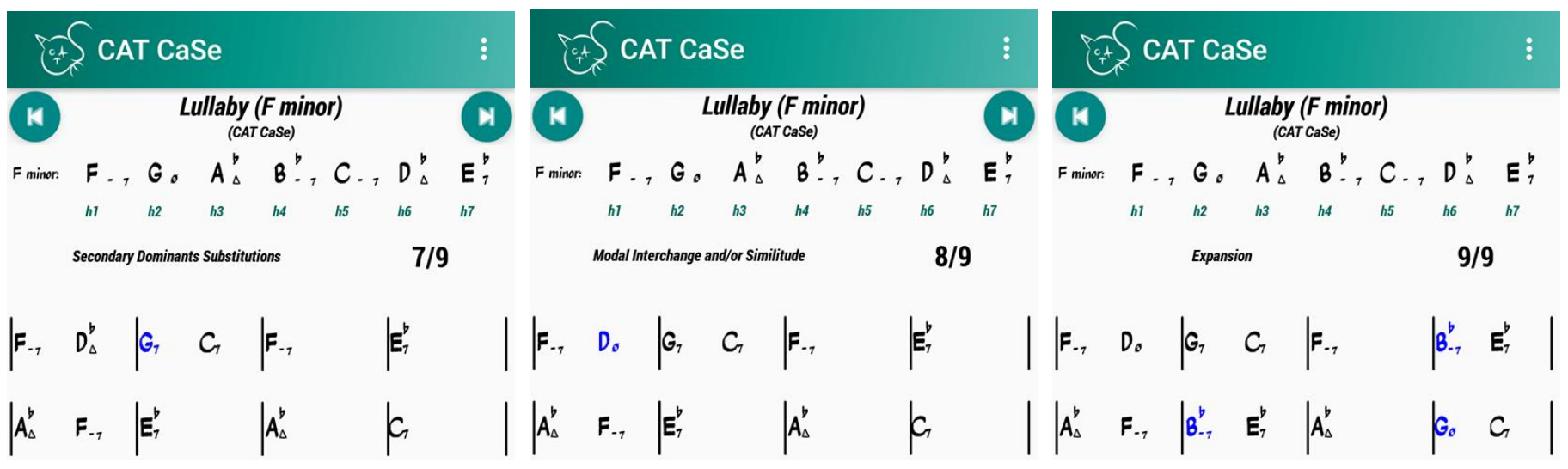

Remarks

It's worth underlining how the chord progression analysis has almost nothing to do with the improvisation built on the original structure. More precisely, net of a certain "Horizontalization" the musician can exploit in facing specific harmonic aggregates, such as "Tonicizations" and "Turnarounds", the improvisation should be carried out "vertically", abiding by the local harmony.

The Local Tonal Centre can be characterized by significant fluctuations: sometimes, it is very difficult to correctly identify it, in particular when a progression cannot be regarded as manifestly "tonal" (built on cadences). And especially in this case, paradoxically, the musician should improvise by abiding by the harmonic progression, chord by chord [12 - 29]. 


\section{References}

[1] Cataldo, C. (2018). The Evolution of Harmonic Progression Analysis: Ultimate CAT. Journal of Science, Humanities and Arts (JOSHA), 5(7). https://dx.doi.org/10.17160/josha.5.7.469

[2] Cataldo, C. (2018). Towards a Music Algebra: Fundamental Harmonic Substitutions in Jazz. International Journal of Advanced Engineering Research and Science, 5(1), 52-57. https://dx.doi.org/10.22161/ijaers.5.1.9

[3] Cataldo, C. (2018). Jazz e Sostituzioni Armoniche: Verso un Nuovo Formalismo - Jazz and Harmonic Substitutions: Towards a New Formalism. Journal of Science, Humanities and Arts (JOSHA), 5(1). https://dx.doi.org/10.17160/josha.5.1.381

[4] Levine, M. (2009). The Jazz Theory Book (Italian Edition by F. Jegher). Milan, IT: Curci Jazz.

[5] Cho, G. J. (1992). Theories and Practice of Harmonic Analysis. Lewiston, NY: E. Mellen Press.

[6] Cork, C. (1988). Harmony by LEGO Bricks: A New Approach to the Use of Harmony in Jazz Improvisation. Leicester, United Kingdom: Tadley Ewing Publications.

[7] Cork, C. (2008). The New Guide to Harmony with LEGO Bricks. London: Tadley Ewing Publications.

[8] Cataldo, C. (2018). Extreme Chord Substitutions: a Qualitative Introduction to CAT (Cataldo Advanced Transformations). Journal of Science, Humanities and Arts (JOSHA), 5(4). https://dx.doi.org/10.17160/josha.5.4.424

[9] Cataldo, C. (2018). Music Algebra: Harmonic Progressions Analysis and CAT (Cataldo Advanced Transformations). International Journal of Advanced Engineering Research and Science, 5(5), 224-227. https://dx.doi.org/10.22161/ijaers.5.5.29

[10] Cataldo, C. (2018). A Simplified Introduction to Music Algebra: from the Scale Vectors to the Modal Tensor. International Journal of Advanced Engineering Research and Science, 5(1), 111-113. https://dx.doi.org/10.22161/ijaers.5.1.16

[11] Cataldo, C. (2018). Algebra Musicale: dai Vettori Scala al Tensore Modale - Music Algebra: from the Scale Vectors to the Modal Tensor. Journal of Science, Humanities and Arts (JOSHA), 5(1). https://dx.doi.org/10.17160/josha.5.1.383

[12] Cataldo, C. (2018). Breve Introduzione all'Improvvisazione Be-Bop [Short Introduction to Be-Bop Improvising]. Journal of Science, Humanities and Arts (JOSHA), 5(6). https://dx.doi.org/10.17160/josha.5.6.448

[13] Cataldo, C., Deidda, S., D’Errico, F., Martino, G. (2018). Definition and Usage of the Be-Bop Minor Scales (part 3): the BeBop Natural Minor Scale. Journal of Science, Humanities and Arts (JOSHA), 5(3). https://dx.doi.org/10.17160/josha.5.3.407

[14] Cataldo, C., Deidda, S., D’Errico, F., Martino, G. (2018). Definition and Usage of the Be-Bop Minor Scales (part 2): the BeBop Dorian Scale. Journal of Science, Humanities and Arts (JOSHA), 5(2). https://dx.doi.org/10.17160/josha.5.2.396

[15] Cataldo, C., Deidda, S., D’Errico, F., Martino, G. (2018). Definition and Usage of the Be-Bop Minor Scales (part 1): the BeBop Melodic Minor Scale. Journal of Science, Humanities and Arts (JOSHA), 5(2). https://dx.doi.org/10.17160/josha.5.2.395

[16] Cataldo, C., Martino, G. (2018). La Scala Maggiore Be-Bop: Definizione ed Utilizzo - The Be-Bop Major Scale: Definition and Usage. Journal of Science, Humanities and Arts (JOSHA), 5(2). https://dx.doi.org/10.17160/josha.5.2.393

[17] Cataldo, C., Martino, G. (2018). La Scala Dominante Be-Bop: Definizione ed Utilizzo - The Be-Bop Dominant Scale: Definition and Usage. Journal of Science, Humanities and Arts (JOSHA), 5(2). https://dx.doi.org/10.17160/josha.5.2.389

[18] Cataldo, C. (2017). Il Linguaggio Be-Bop e gli Accordi di Settima di Quarta Specie [The Be-Bop Language and The Major Seventh Chords]. Journal of Science, Humanities and Arts (JOSHA), 4(4). https://dx.doi.org/10.17160/josha.4.4.341

[19] Cataldo, C. (2017). The Art of Improvising: the Be-Bop Language and the Major Seventh Chords. Art and Design Review, 5, 222-229. https://doi.org/10.4236/adr.2017.54018

[20] Cataldo, C. (2017). Il Linguaggio Be-Bop e gli Accordi di Settima di Seconda Specie [The Be-Bop Language and The Minor Seventh Chords]. Journal of Science, Humanities and Arts (JOSHA), 4(4). https://dx.doi.org/10.17160/josha.4.4.339

[21] Cataldo, C. (2017). The Art of Improvising: the Be-Bop Language and the Minor Seventh Chords. Art and Design Review, 5, 213-221. https://doi.org/10.4236/adr.2017.54017

[22] Cataldo, C. (2017). Il Linguaggio Be-Bop e gli Accordi di Settima di Prima Specie [The Be-Bop Language and The Dominant Seventh Chords]. Journal of Science, Humanities and Arts (JOSHA), 4(4). https://dx.doi.org/10.17160/josha.4.4.340

[23] Cataldo, C. (2017). The Art of Improvising: the Be-Bop Language and the Dominant Seventh Chords. Art and Design Review, 5, 181-188. http://doi.org/10.4236/adr.2017.53014

[24] Wise. L. (1983). Bebop Bible - The Musicians Dictionary of Melodic Lines. United States: REH Publications.

[25] Coker, J., Casale, J., \& Campbell, G. (1982). Patterns for Jazz. Los Angeles, CA: Alfred Publishing Co. Inc.

[26] Baker, D. (1988). How to Play Bebop (Volume 1). Los Angeles, CA: Alfred Publishing Co. Inc.

[27] Baker, D. (1988). How to Play Bebop (Volume 2). Los Angeles, CA: Alfred Publishing Co. Inc.

[28] Baker, D. (1988). How to Play Bebop (Volume 3). Los Angeles, CA: Alfred Publishing Co. Inc.

[29] Baker, D. (1988). Jazz Improvisation. Los Angeles, CA: Alfred Publishing Co. Inc. 